\title{
PENGARUH GAYA KEPEMIMPINAN DAN LINGKUNGAN KERJA TERHADAP KEPUASAN KERJA KARYAWAN POLITEKNIK NEGERI BATAM
}

\author{
Slamet Soebagiyo, Yulina Eva Riany dan Tita Rosita \\ Universitas Terbuka, Indonesia \\ Institut Pertanian Bogor (IPB) Jawa Barat, Indonesia \\ Email: slametsby75new@gmail.com,yriany@apps.ipb.ac.id dan tita@ecampus.ut.ac.id
}

\section{Abstract}

Employee job satisfaction is an important factor in the management of human resources in an organization. Organizations that are able to create employee job satisfaction have added value for the employees of the organization. Employee job satisfaction is influenced by several factors including leadership factors and work environment factors. In the work environment factor, the non-physical aspects of the work environment, namely in the form of coworker relationships, are a similar factor to the leadership factor, where both of these factors emphasize the aspects of the relationship between individuals in the organization. This study aims to analyze the influence of leadership style and work environment, in this case, the relationship between colleagues on employee job satisfaction. The sample of this research is the employees of Politeknik Negeri Batam, amounting to 117 respondents and using simple random sampling technique. The data collection technique used an online questionnaire. Data analysis used multiple linear regression and the data were processed using the SPSS version 25 application. The results showed that the leadership style and work environment, in this case, the relationship between colleagues and colleagues has a positive effect on job satisfaction of Politeknik Negeri Batam employees.

Keywords: leadership style; work environment; job satisfaction
Abstrak
Kepuasan kerja karyawan merupakan hal yang penting dalam pengelolaan sumber daya manusia di dalam sebuah organisasi. Organisasi yang mampu menciptaan kepuasan kerja karyawan memiliki nilai tambah bagi karyawan organisasi tersebut. Kepuasan kerja karyawan dipengaruhi oleh beberapa faktor diantaranya faktor kepemimpinan dan faktor lingkungan kerja. Pada faktor lingkungan kerja, aspek lingkungan kerja non fisik yaitu berupa hubungan rekan sekerja merupakan faktor serupa dengan faktor kepemimpinan, dimana kedua faktor tersebut sama-sama menekankan pada aspek hubungan antar individu dalam organisasi. Penelitian ini bertujuan untuk menganalisis pengaruh gaya kepemimpinan dan lingkungan kerja, dalam hal ini hubungan rekan sekerja terhadap kepuasan kerja karyawan. Sampel penelitian ini adalah karyawan Politeknik Negeri Batam yang berjumlah 117 responden dengan menggunakan teknik simple random sampling. Teknik

$\begin{array}{ll}\text { How to cite: } & \text { Soebagiyo, Slamet., Yulina Eva Riany dan Tita Rosita (2021) Pengaruh Gaya Kepemimpinan dan } \\ & \text { Lingkungan Kerja terhadap Kepuasan Kerja Karyawan Politeknik Negeri Batam. Syntax Literate. 6(5). } \\ & \text { http://dx.doi.org/10.36418/syntax-literate.v6i5.2743 } \\ \text { E-ISSN: } & \text { 2548-1398 } \\ \text { Published by: } & \text { Ridwan Institute }\end{array}$


pengumpulan data menggunakan kuesioner daring. Analisa data menggunakan regresi linear berganda dan data diolah dengan menggunnakan aplikasi SPSS versi 25. Hasil penelitian menunjukkan bahwa gaya kepemimpinan dan lingkungan kerja dalam hal ini hubungan rekan sekerja berpengaruh positif terhadap kepuasan kerja karyawan Politekknik Negeri Batam.

Kata Kunci: gaya kepemimpinan; lingkungan kerja; kepuasan kerja

\section{Pendahuluan}

Manusia dalam kehidupan sosial akan selalu berada dalam sebuah organisasi. Organisasi merupakan suatu unit sosial yang dikoordinasi secara sadar, terdiri atas dua atau lebih orang-orang yang berfungsi dalam suatu basis yang kontinu untuk mencapai suatu tujuan bersama atau serangkaian tujuan (P. Stephe. dan Timothy A. Judge Robbins, 2018). Organisasi dalam melaksanakan aktivitasnya untuk mencapai tujuannya tidak dapat dilepaskan dari lingkungannya. Dalam organnisasi formal yang didalamnya terdapat interaksi sosial antara atasan dan bawahan. Gaya kepemimpinan dan lingkungan kerja, dalam hal ini hubungan rekan kerja dapat mempengaruhi kepuasan kerja karyawan. Pengelolaan faktor lingkungan kerja dan faktor sumber daya manusia merupakan hal penting dalam sebuah organisasi dikarenakan hal tersebut terkait dengan kepuasan kerja karyawan. Faktor-faktor yang berpengaruh terhadap kepuasan kerja diantaranya adalah upah (kompensasi), pekerjaan, kesempatan promosi, penyelia, dan rekan sekerja (Gibson, 2010) dalam (Edison, Anwar, \& Komariyah, 2016). Selain itu faktor lingkungan kerja juga berpengaruh terhadap kepuasan kerja (Nitisemito, 2000: 183). Disisi lain terdapat empat cara untuk mengungkapkan ketidakpuasan kerja, yaitu: keluar (exit) yaitu mencari pekerjaan lain, menyuarakan (voice) memberikan saran kepada atasan, mengabaikan (neglect) yaitu membiarkan keadaan menjadi lebih buruk, dan kesetiaan (loyalty) yaitu menunggu secara pasif (P. Stephe. \&. Mary Coulter Robbins, 2016).

Politeknik Negeri Batam sebagai lembaga pendidikan tinggi vokasi milik pemerintah yang memiliki tugas mencerdaskan kehidupan bangsa ini. Tata kelola sumber daya manusia yang tidak baik dapat menimbulkan kekacauan dalam organisasi. Kondisi lingkungan kerja yang tidak kondusif dapat memunculkan masalah-masalah baru. Berdasarkan data dari hasil observasi awal peneliti, diperoleh data jumlah karyawan Politeknik Negeri Batam yang mengundurkan diri (resign) sejak tahun 2013 hingga tahun 2018 tercatat total berjumlah 39 orang karyawan. Rincian data pertahun bisa dilihat pada tabel 1 berikut: 
Tabel 1

Jumlah karyawan yang mengundurkan diri per 31 Desember 2018

\begin{tabular}{cc}
\hline Tahun & Jumlah (orang) \\
\hline 2013 & 4 \\
\hline 2014 & 7 \\
\hline 2015 & 5 \\
\hline 2016 & 9 \\
\hline 2017 & 6 \\
\hline 2018 & 8 \\
\hline
\end{tabular}

Sumber: Data primer kepegawaian (2019)

Survei awal peneliti menunjukkan terdapat hal-hal lain yang dapat menimbulkan ketidakpuasan karyawan seperti: beban kerja yang diberikan oleh atasan yang tidak merata dan tidak berdasarkan prinsip keadilan, kurangnya apresiasi atau penghargaan yang diberikan pimpinan kepada karyawan atas ide-ide atau sumbang saran yang telah disampaikan, perlakuan atau penghargaan yang diberikan pimpinan kepada karyawan yang didasarkan pada faktor kedekatan bukan karena prestasi bawahan, serta masih kurangnya tingkat kedisiplinan karyawan untuk melaksanakan ketentuan yang sudah ditetapkan oleh organisasi.

(Steven P Robbins dan Timothy A Judge., 2015) mendefinisikan kepemimpinan sebagai kemampuan untuk mempengaruhi suatu kelompok menuju pencapaian sebuah visi atau tujuan yang ditetapkan. Dari definisi tersebut dapat dilihat bahwa memimpin berhubungan dengan satu orang yang mempengaruhi orang lain dalam kelompok yang bersangkutan. (Rivai \& Mulyadi, 2003, 2007) menyatakan bahwa gaya kepemimpinan adalah pola menyeluruh dari tindakan seorang pemimpin, baik yang tampak maupun yang tidak tampak oleh bawahannya. Gaya kepemimpinan menggambarkan kombinasi yang konsisten dari falsafah, keterampilan, sifat, dan sikap yang mendasari perilaku seseorang.

Teori kepemimpinan di era tahun 1960-an muncul konsep kepemimpinan manajerial, dimana dalam konsep ini kepemimpinan menekankan perhatian pada dua hal yaitu perhatian terhadap produksi/tugas dan perhatian terhadap manusia. (Rivai \& Mulyadi, 2007) menjelaskan berdasarkan teori ini maka gaya kepemimpian dikelompokkan dalam empat gaya dasar kepemimpinan: (1) gaya manajemen tugas, pemimpin memberikan perhatian tinggi terhadap produksi, tetapi perhatian rendah terhadap manusia, (2) gaya manajemen Country club, pemimpin memberikan perhatian tinggi terhadap manusia, tetapi perhatian rendah terhadap produksi, (3) gaya manajemen miskin, dimana pemimpin tidak terlalu menunjukkan perhatian, baik terhadap produksi maupun manusia, (4) gaya manajemen tim, pemimpin menunjukkan perhatian tinggi baik terhadap produksi maupun terhadap manusia. 
Lingkungan kerja merupakan sebuah tempat dimana seseorang melaksanakan peran, tugas dan fungsinya dalam melaksanakan pekerjaan. (Nitisemito, 2000) menyatakan bahwa lingkungan kerja adalah segala sesuatu yang ada di sekitar para pekerja dan yang dapat mempengaruhi dirinya dalam menjalankan tugas-tugas yang dibebankan. (Kasmir, 2018) menyatakan bahwa lingkungan kerja merupakan suasana atau kondisi disekitar tempat kerja dapat berupa ruangan, layout, sarana, dan prasana, serta hubungan kerja sesama rekan kerja. (Kasmir, 2018) menyatakan bahwa lingkungan kerja merupakan suasana atau kondisi disekitar tempat kerja dapat berupa ruangan, layout, sarana, dan prasana, serta hubungan kerja sesama rekan kerja.

Menurut (Sedarmayanti, 2009) menyatakan bahwa faktor-faktor lingkungan kerja meliputi penerangan, suhu udara, suara bising, penggunaan warna, ruang gerak yang diperlukan, keamanan kerja, dan hubungan karyawan. (Nitisemito, 2000) menyatakan bahwa lingkungan kerja non fisik juga mencerminkan kondisi yang mendukung kerjasama antara tingkat atasan dengan bawahan maupun sesama rekan kerja yang memiliki status jabatan sama di perusahaan.

Kepuasan kerja karyawan dapat memberikan dampak positif bagi produktifitas organisasi. (Wibowo, 2016) menyatakan kepuasan kerja merupakan tingkat kepuasan senang seseorang sebagai penilaian positif terhadap pekerjaannya dan lingkungan tempat pekerjaannya. (Gibson, Ivancevich, 1997) menyatakan kepuasan kerja adalah sikap individu mengenai pekerjaan. Sikap ini mungkin bersifat positif (puas) atau negative (tidak puas). (Sedarmayanti, 2017) menyatakan bahwa terdapat tiga teori tentang kepuasan kerja yaitu Discrepancy Theory (Teori Ketidaksesuaian) dimana kepuasan kerja dihitung dari selisih antara sesuatu yang seharusnya dan kenyataan yang dirasakan, kepuasan kerja bergantung pada selisih antara sesuatu yang dianggap akan didapat dengan apa yang dicapai. Equality Theory (Teori Keadilan) menjelaskan bahwa orang akan merasa puas/tidak puas tergantung pada ada/tidaknya keadilan dalam situasi kerja. Komponen utama teori ini adalah input, hasil, keadilan dan ketidakadilan. Konsep Two Factor Theory (Teori Dua Faktor) menjelaskan bahwa kepuasan dan ketidakpuasan merupakan hal yang berbeda. Karakteristik pekerjaan menurut teori dua faktor yaitu: statisfies/motivator: faktor/situasi yang dibutuhkan sebagai sumber kepuasan kerja, terdiri atas pekerjaan menarik penuh tantangan, ada kesempatan berprestasi, serta kesempatan memperoleh penghargaan dan promosi; terpenuhinya faktor ini akan menimbulkan kepuasan, namun jika tidak terpenuhi faktor ini tidak selalu mengakibatkan ketidakpuasan; faktor yang lain yaitu Dissatisfies (hygiene factors) dimana faktor-faktor yang menjadi sumber ketidakpuasan adalah gaji/upah, pengawasan, hubungan antar pribadi, kondisi kerja, dan status. Faktor-faktor tersebut diperlukan untuk memenuhi dorongan biologis dan kebutuhan dasar pegawai. Jika faktor tersebut tidak terpenuhi, pegawai tidak puas. Namun, jika besarnya faktor ini memadai untuk memenuhi kebutuhan, pegawai tidak kecewa meski belum puas.

Menurut (Luthan, 2006) menyatakan terdapat lima dimensi yang mempengaruhi kepuasan kerja yaitu: pekerjaan itu sendiri, gaji, kesempatan promosi, pengawasan supervisor, dan rekan kerja. Dalam penelitian ini gaya kepemimpinan supervisor dan 
lingkungan kerja dalam hal ini hubungan rekan sekerja mempengaruhi kepuasan kerja karyawan.

Hasil penelitian menunjukkan bahwa rekan kerja dan supervisi secara parsial dan secara simultan memiliki pengaruh positif pada kepuasan kerja karyawan (Suciadi \& Wijaya, 2017). Dalam penelitian ini peneliti membatasi hanya pada faktor gaya kepemimpinan dan faktor lingkungan kerja dalam hal ini hubungan rekan kerja terhadap kepuasan kerja karyawan. Sehingga penelitian ini akan menjawab beberapa pertanyaan berikut ini: 1. Bagaimana pengaruh gaya kepemimpinan terhadap kepuasan kerja karyawan Politeknik Negeri Batam? 2. Bagaimana pengaruh lingkungan kerja dalam hal ini hubungan rekan kerja terhadap kepuasan kerja karyawan Politeknik Negeri Batam?, 3. Bagaimana pengaruh gaya kepemimpinan dan lingkungan kerja dalam hal ini hubungan rekan kerja mempengaruhi kepuasan kerja karyawan Politeknik Negeri Batam? Tujuan penelitian ini adalah untuk: 1. Menganalisis pengaruh gaya kepemimpinan terhadap kepuasan kerja karyawan Politeknik Negeri Batam. 2. Menganalisis pengaruh lingkungan kerja dalam hal ini hubungan rekan kerja terhadap kepuasan kerja karyawan Politeknik Negeri Batam. 3. Menganalisis secara bersamasama pengaruh gaya kepemimpinan dan lingkungan kerja dalam hal ini hubungan rekan kerja terhadap kepuasan kerja karyawan Politeknik Negeri Batam. Manfaat teoritis dari penelitian ini adalah: a. Untuk menambah pengembangan ilmu pengetahuan, khususnya dalam bidang manajemen sumber daya manusia. b. Untuk memberikan sumbangan pemikiran khususnya dalam kaitannya dengan peningkatan kepuasan kerja karyawan. c. Sebagai bahan kajian pada penelitian-penelitian selanjutnya yang berhubungan dengan tema yang sama secara lebih mendalam dan memiliki cakupan yang lebih luas. 2. Manfaat praktis pada penelitian ini adalah: a. Bagi jajaran pimpinan Politeknik Negeri Batam, sebagai masukan untuk menyusun program pengembangan sumber daya manusia bagi karyawan dan penyelia, khususnya dalam aspek kepemimpinan, lingkungan kerja dan kepuasan kerja karyawan. b. Bagi peneliti sebagai penambah wawasan serta membantu berfikir secara ilmiah dalam bidang manajemen sumber daya manusia.

\section{Metode Penelitian}

Penelitian ini adalah penelitian explanatory dengan menggunakan pendekatan kuantitatif. Penelitian ini ingin menjelaskan pengaruh gaya kepemimpinan dan lingkungan kerja (rekan sekerja) terhadap kepuasan kerja karyawan Politeknik Negeri Batam. Populasinya adalah karyawan Politeknik Negeri Batam yang berjumlah 166 orang yang bekerja di lokasi kampus Politeknik Negeri Batam di jalan Jenderal Ahmad Yani Kecamatan Batam Kota, Batam, Provinsi Kepulauan Riau. Sampel dalam penelitian ini diambil dengan cara simple random sampling. Jumlah sampel dalam penelitian ini adalah 117 responden dengan tingkat kesalahan yang ditoleransi sebesar $5 \%$. Instrumen yang digunakan dalam penelitian ini adalah kuesioner dengan pertanyaan tertutup yang disebarkan ke responden secara daring pada bulan Desember 
2019 sampai dengan bulan Februari 2020. Penelitian ini menggunakan data primer dan data sekunder.

Langkah-langkah pengumpulan data primer dilakukan melalui beberapa tahapan yaitu: 1.Penyusunan kuesioner dengan skala likert. 2. Melakukan uji coba kuesioner. 3. Penyebaran kuesioner. 4. Pengumpulan hasil kuesioner. 5. Pengolahan data dilakukan dengan menggunakan program SPSS 25 for Windows.

Pengujian instrumen penelitian dilakukan melalui uji asumsi klasik yaitu uji normalitas, uji multikolinieritas dan uji heteroskedastis. Metode analisis yang digunakan pada penelitian ini adalah analisis linier berganda. Sebelum melaksanakan penelitian, perlu dilakukan uji validiitas dan realibilitas terhadap pernyataan-pernyataan yang terdapat pada kuesioner. Pengaruh variabel independen terhadap variabel dependen diuji dengan tingkat kepercayaan 95\% atau $\alpha: 0,05$. Uji validitas menggunakan teknik metode korelasi bivariet dengan nilai r-Tabel 0,361. Hasil uji validitas pada kuesioner untuk variabel gaya kepemimpinan (X1), variabel rekan sekerja (X2) dan variabel kepuasan kerja (Y) seluruh indicator menunjukkan nilai r-Hitung > r-Tabel. Untuk melakukan uji realibilitas, penelitian ini menggunkan metode Cronbach's Alpha. Jika nilai Cronbach's Alpha > 0,6 berarti item-item pada kuesioner memiliki nilai keandalan yang tinggi. Hasil uji realibilitas untuk masing-masing variabel pada penelitian ini dapat dilihat pada tabel 2 dibawah ini.

Tabel 2

Hasil uji realibilitas variabel penelitian

\begin{tabular}{lcc}
\hline \multirow{2}{*}{ Variabel } & \multicolumn{2}{c}{ Reliability Statistics } \\
\cline { 2 - 3 } & $\begin{array}{c}\text { Cronbach's } \\
\text { Alpha }\end{array}$ & N of Items \\
\hline \hline Gaya kepemimpinan & 0.986 & 14 \\
\hline Lingkungan kerja (Rekan kerja) & 0.993 & 14 \\
\hline Kepuasan kerja & 0.985 & 15 \\
\hline
\end{tabular}

Sumber: Data primer (2020)

Hasil analisis menunjukkan keseluruhan nilai Cronbach's Alpha variabelvariabel tersebut memenuhi kriteria uji realibilitas karena melebihi nilai batas uji realibiilitas yaitu 0,6. Metode penelitian yang digunakan dalam pemecahan permasalahan termasuk metode analisis. Keterangan gambar diletakkan menjadi bagian dari judul gambar (figure caption) bukan menjadi bagian dari gambar. Metode-metode yang digunakan dalam penyelesaian penelitian dituliskan di bagian ini.

\section{Hasil dan Pembahasan}

Dalam regresi linier berganda, model regresi yang baik adalah memiliki nilai residual yang berdistribusi normal. Metode yang digunakan dalam penelitian ini adalah menggunakan model P-Plot. 


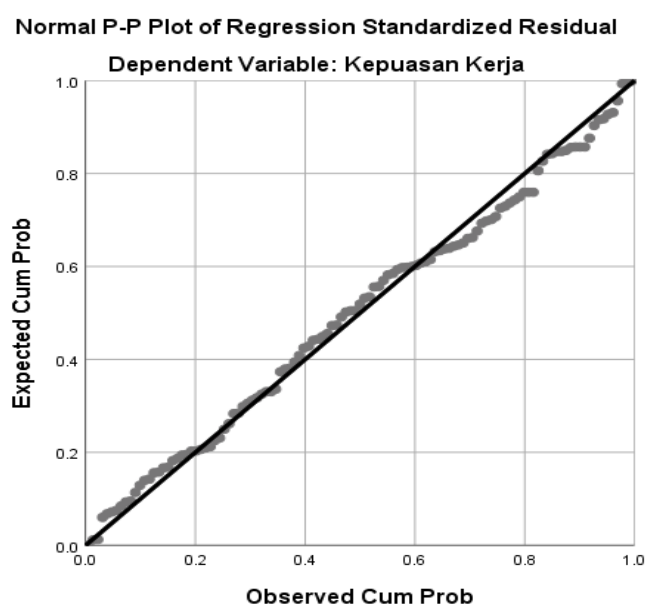

Gambar 1

Hasil Uji Normalitas model P-Plot

Sumber: Hasil penelitian, 2020 (data diolah)

Hasil uji dengan P-Plot memperlihatkan data (titik-titik) berada dekat dengan garis dan mengikuti arah garis diagonal, sehingga hal ini menunjukkan data dalam penelitian ini normal.

Tabel 3

Hasil Uji Multikolinearitas

Coefficients $^{\text {a }}$

\section{Unstandardized Standardized Collinearity}

\begin{tabular}{|c|c|c|c|c|c|c|c|}
\hline \multirow{2}{*}{ Model } & \multicolumn{2}{|c|}{ Coefficients } & \multirow{2}{*}{$\begin{array}{c}\text { Coefficients } \\
\text { Beta }\end{array}$} & \multirow{2}{*}{$\mathbf{T}$} & \multirow{2}{*}{ Sig. } & \multicolumn{2}{|c|}{ Statistics } \\
\hline & B & $\begin{array}{l}\text { Std. } \\
\text { Error }\end{array}$ & & & & Tolerance & VIF \\
\hline 1 (Constant) & 15.771 & 3.149 & & 5.008 & .000 & & \\
\hline $\begin{array}{l}\text { Gaya } \\
\text { Kepemimpinan }\end{array}$ & .241 & .064 & .289 & 3.791 & .000 & .573 & 1.746 \\
\hline Rekan Sekerja & .520 & .070 & .567 & 7.437 & .000 & .573 & 1.746 \\
\hline
\end{tabular}

a. Dependent Variable: Kepuasan Kerja

Sumber: Hasil penelitian, 2020 (data diolah)

Nilai Tolerance adalah 0,573 , yang artinya nilai Tolerance $>0,100$. Nilai VIF adalah 1,746, yang artinya nilai $\mathrm{VIF}<10,00$. maka dapat dinyatakan bahwa model pada penelitian ini terbebas dari uji multikolinearitas. 


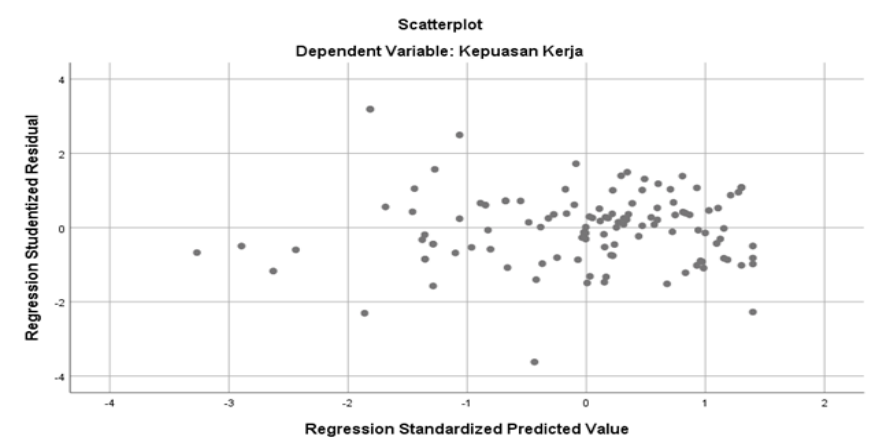

Gambar 2

Hasil Uji Heterokedastisitas

Sumber: Hasil penelitian, 2020 (data diolah)

Tidak ada pola yang jelas serta titik-titik menyebar diatas dan dibawah angka 0 pada sumbu Y. Maka dapat disimpulkan model bebas dari gejala heterokedastisitas dan layak digunakan dalam penelitian.

Tabel 4

Hasil Uji Koefisiensi Determinasi

\begin{tabular}{ccccc}
\hline \multicolumn{4}{c}{ Model Summary } \\
\hline Model & R & R Square & $\begin{array}{c}\text { Adjusted R } \\
\text { Square }\end{array}$ & $\begin{array}{c}\text { Std. Error of the } \\
\text { Estimate }\end{array}$ \\
\hline 1 & $.787^{\text {a }}$ & .620 & .613 & 6.27207 \\
\hline a. Predictors: (Constant), Rekan Sekerja, Gaya Kepemimpinan \\
\hline \multicolumn{4}{r}{ Sumber: Hasil penelitian, 2020 (data diolah) }
\end{tabular}

Sumber: Hasil penelitian, 2020 (data diolah)

Hasil uji koefisiensi determinasi $\left(\mathrm{R}^{2}\right)$ adalah 0,62 yang menjelaskan bahwa variabel Gaya Kepemimpinan dan Lingkungan kerja (Rekan Sekerja) memberi pengaruh sebesar $62 \%$ terhadap Kepuasan Kerja.

\section{Tabel 5}

Hasil Uji F

\begin{tabular}{lll|c|c|c|c}
\hline & \multicolumn{7}{c}{ ANOVA $^{\text {a }}$} \\
& \multicolumn{1}{c}{ Model } & Sum of Squares & Df & Mean Square & F & Sig. \\
\hline 1 & Regression & 7317.234 & 2 & 3658.617 & 93.003 & $.000^{\mathrm{b}}$ \\
\cline { 2 - 8 } & Residual & 4484.629 & 114 & 39.339 & & \\
\hline & Total & 11801.863 & 116 & & & \\
\hline
\end{tabular}

a. Dependent Variable: Kepuasan Kerja

b. Predictors: (Constant), Rekan Sekerja, Gaya Kepemimpinan

Sumber: Hasil penelitian, 2020 (data diolah)

Hasil uji nilai F Hitung adalah 93,003 lebih besar ( $>$ ) nilai $\mathrm{F}$ tabel yaitu 3,08. Sedangkan nilai Signifikansi 0,000 lebih kecil (<) nilai Signifikansi 0,05. Hasil Uji F 
menunjukkan bahwa nilai $\mathrm{F}$ Hitung adalah 93,003 yang berarti nilai $\mathrm{F}$ Hitung lebih besar dari nilai F Tabel 3,08. Dari hasil Uji F ini menyimpulkan adanya pengaruh secara bersama-sama variabel Gaya Kepemimpinan (X1) dan variabel Rekan Sekerja (X2) terhadap variabel Kepuasan Kerja (Y).

\section{Kesimpulan}

Hasil penelitian dapat disimpulkan bahwa: 1. Gaya kepemimpinan berpengaruh positif terhadap kepuasan kerja karyawan Politeknik Negeri Batam; 2. Lingkungan kerja dalam hal ini rekan sekerja berpengaruh secara positif terhadap kepuasan kerja karyawan Politeknik Negeri Batam; 3. Gaya kepemimpinan dan lingkungan kerja (rekan sekerja) secara bersama-sama berpengaruh positif terhadap kepuasan kerja karyawan Polteknik Negeri Batam 
Pengaruh Gaya Kepemimpinan dan Lingkungan Kerja terhadap Kepuasan Kerja Karyawan Politeknik Negeri Batam

\section{BIBLIOGRAFI}

Edison, Emron, Anwar, Yohny, \& Komariyah, Imas. (2016). Manajemen sumber daya manusia. Bandung: Alfabeta. Google Scholar

Gibson, Ivancevich, Donnelly. (1997). Organisasi (Jilid 2). Tangerang: Binarupa Aksara Publisher.

Gibson. (2010). Organisasi dan Manajemen: Perilaku, Struktur, dan Proses (Keempat). Jakarta: Erlangga.

Kasmir. (2018). Manajemen Sumber Daya Manusia Teori dan Praktik (Cetakan Ke). Jakarta: Penerbit PT. Raja Grafindo Persada.

Luthan, Fred. (2006). Perilaku Organisasi.(edisi ke-10). Bahasa Indonesia. Yogyakarta: Andi Offset. Google Scholar

Nitisemito, A. S. (2000). Manajemen Personalia. Jakarta: Ghalia Indonesia.

Rivai, Veithzal, \& Mulyadi, Deddy. (2003). Kepemimpinan dan perilaku organisasi. Jakarta: Raja Grafindo Persada. Google Scholar

Rivai, Veithzal, \& Mulyadi, Deddy. (2007). Kepemimpinan dan Perilaku Organisasi, Jakarta: PT. Raja Grafindo Persada. Google Scholar

Robbins, P. Stephe. \&. Mary Coulter. (2016). Management (Thirteenth). Pearson: USA. Google Scholar

Robbins, P. Stephe. dan Timothy A. Judge. (2018). Perilaku Organisasi. Jakarta: Salemba Empat. Google Scholar

Sedarmayanti. (2009). Tata Kerja dan Produktivitas Kerja. Bandung: Mandar Maju. Google Scholar

Sedarmayanti. (2017). Manajemen Sumber Daya Manusia. Bandung: Mandar Maju Google Scholar

Steven P Robbins dan Timothy A Judge. (2015). Perilaku Organisasi. Jakarta: Penerbit Salemba Empat. Google Scholar

Suciadi, Ivan, \& Wijaya, Michael Angelo. (2017). Analisa Pengaruh Pekerjaan Itu Sendiri, Kompensasi, Rekan Kerja, Dan Kepemimpinan Terhadap Kepuasan Kerja Karyawan Bagian Operasional Restoran Carnivor Steak and Grill Surabaya. Jurnal Hospitality dan Manajemen Jasa, 5(2). Google Scholar

Wibowo. (2016). Perilaku Dalam Organisasi Edisi Kedua. Jakarta: PT. Raja Grafindo Persada. Google Scholar 
Soebagiyo Slamet, Yulina Eva Riany dan Tita Rosita

\section{Copyright holder:}

Bambang Kriswantara, Kurniawati dan Hilman F. Pardede (2021)

First publication right:

Journal Syntax Literate

This article is licensed under:

(c) $\mathrm{E}_{\mathrm{EY}} \ominus$ 